swelling which was diffused over the whole area of the breast. The nipple was not prominent and there was no discharge. On the 10th the breast was amputated as malignant disease was suspected. Histologically the growth was a fibro-adenoma. The patient returned to the hospital on July 1st, 1899, with a second fibro-adenoma in the right breast.

Most text-books on surgery dismiss the subject of cancer of the male breast very briefly and Sheild, ${ }^{7}$ although discussing the disease at greater length, says that "the symptoms and course are precisely similar to what is found in females." From a study of all the cases with which I am acquainted some facts may be deduced which show that the disease in men does not follow quite the same course as it does in women. The differences may be of minor importance but still are worthy of record. They may be arranged under the following heads: (1) age; (2) side affected; (3) duration; and (4) presence of ulceration.

1. Age. - The age at which the disease occurs varies from 12 to 91 years. In nine cases which I have collected the average age was 615 years; this is somewhat higher than that given by $R$. Williams who gives 50 years as the mean. Possibly the difference is due partly to the fact that I have only taken the average of a very small number of cases and partly because in my series Lunn's case is included, the age of his patient being 91 years. At all events, the average age at which the disease occurs in men is many years later than in women; in the latter Sheild says it is most common between 40 and 60 years. Quite recently Leaf, ${ }^{8}$ who has investigated 100 cases of cancer of the breast in women, found that the average age at which the disease commences is 49 years two months. Bland.Sutton ${ }^{\theta}$ says it is most common between 40 and 50 years; Watson Cheyne ${ }^{10}$ between 35 and 60 years; and Pick ${ }^{11}$ ketween 35 and 55 years. Moreover, a relatively large number of the cases in men commence over the age of 70 years or between 60 and 70 years (Warfield).

2. Side of the body affected.-In women carcinoma of the breast is more often tound on the left side, whereas the opposite is the case in men. Out of 31 cases quoted by Wagstaffe 16 had the right breast affected and 12 the left; in three instances both sides were diseased. Since the publication of these I have collected 11 cases and of this series the right breast was implicated eight times and the left three, showing that the disease occurs nearly three times as frequently on the right as on the left side.

3. Duration. - In 13 cases the length of time that the growth had been noticed by the patient is mentioned; ten years is the longest and three months is the shortest, the mean being 3.36 years. (R. Williams gives 3.16 years.) In women the average duration is somewhat less than this. I am unable to give the total duration of life as in most of the cases it is not recorded, but Warfield mentions one case where the patient lived 35 years. In Wagstaffe's paper the duration of life is given in 30 cases: 11 lived under one year, eight rather more than one year, one over two years, three cver three years, five over four years, and two over eight years, the average being 163 years.

4. Presence of ulceration.-In a large proportion of the patients who present themselves for treatment a'ceration of the growth is found. In 12 cases where any mention of the appearance of the breast is made seven were in a state of ulceration, whilst two others presented a dusky red colour and were evidently on the point of breaking down. In one case the ulcer was five inches in diameter. Wagstaffe states that in more than half the number of cases ulceration is present when the patient is first seen. Schuchardt ${ }^{12}$ found that in 61 out of 70 cases ulceration was present.

Although a histcry of previous injury to the brea: $t$ can often be obtained in women as well as in men, yet in the latter the history seems, as a rule, to be much more definite. Another point that I have observed is the frequency with which the growth starts in or around the nipple. In the $3^{7}$ cases collected by Warfield the nipple was involved in 18 . This site for a tumour of the breast is also seen in women but in the latter the neoplasm is usually a duct carcinoma, whereas this form of growth is exceedingly rare in men.

The treatment which should be adopted is, as in women, 7 Diseases of the Breast. 1898.

8 The Clinical Causes of Cancer of the Breast and itg Prevention, 1904. 8 Tumours, Innocent and Malignant. 1903.

10 Treveg's System of Surgery, 1896.

12 Archives ftir Klinische Chirurgie, Band xxxi., Heft 1, 1884. removal of the whole breast, the skin over the breast, the fascia covering the pectoralis major (and the muscle itself if involved), and all the fat and cellular tissue in the axilla. As in the female, if the growth only is excised recurrence quickly follows. Provided that the growth is not too extensive for removal the prognosis after oferation is good.

In conclusion I am much indebted to Dr. Purcell, Mr. Jessett, and Mr. Waterhouse for rermission to publish their cases; also to Dr. T. J. English for the excellent photograpls which he was kind enough to take for me.

Wimpole-street, $\mathrm{W}$.

\section{A CASE OF CONGENITAL DEFICIENCY OF BOTH UPPER LIMBS.}

\section{By H. ASHLEY GaItskell, M.D. Cantab.,} IATE HOUSE SURGEON TO GUY'S HOSPITAL.

THE following is an account of a case of congenital deficiency of the upper limbs and as this is a condition of rare occurrence $I$ consider it worth recording.

On March 2nd, 1902, I was called to a woman four miles away in a country village in Northamptonshire who was stated to be in labour. When $I$ arrived I found her up and walking about. On inquiry the pain did not seem to be severe enough for labour pains. I asked ker when she expected to be confined and was told that it was not due for another month. I thought that it was advisable, however, to make an examination as there had been a considerable amount of "flooding." The abdomen was distended and the uterus was evidently enlarged, the enlargemnt corresponding to about the eighth month of pregnancy. The os was only slightly dilated and a soft mass projected from it which proved to be a small clot of blood. Beyond this $I$ could with difficulty feel the head. Thinking it possible to stave off labour I prescribed opium and rest. I saw the patient on the next day and hæmorrhage had ceased. Two days later, however, I received an urgent message stating that the "waters bad burst," and asking me to come at once. On arrival at the patient's house I was told that the child was already born but that he possessed no arms. I examined the child and found that he was alive but was evidently premature, about ejght months as I expected. There was total absence of any signs of arms but otherwise the child was complete in every respect. I did not think be would live but requested the mother to allow me to have him photographed. The child, however, died in two days but $I$ managed to secure a photograph of his body (Fig. 1). I also obtained permission to make a post-mortem examination, explaining that it was a case of considerable rarity and the opportunity ought not to be missed.

It was difficult to make out on feeling through the skin the existence of any clavicles or scapulæ, so I made an incision through the skin on the left side and a careful dissection revealed their preserce; these were preserved in formalin and put aside till the opportunity arose for an accurate dissection of the parts, as I wished to know what had become of the glenoid cavity of the scapula and the muscles which normally arise from the clavicle or scapula and are inserted into the humerns. The arrangement $I$ did find was as follows and is not without interest. Over the acromio clavicular joint and arising from its ligaments was a dense aponeurosis (Fig. 2) and into this most of the muscles were inserted (as far as I could make out from the smallness of the muscles I had to deal with). In the posterior region the supraspinatus, infraspinatus, and teres minor all arose from their normal places on scapula and were inserted into this same aponeurosis over the acromioclavicular joint. There were no signs of the teres major, deltoid, or of the triceps. The aponeurosis arose from all those parts where the deltoid normally arises-namely, the spine of the scapula and the clavicle. Of the pectoral muscles I could only find one and this also was inserted into the aponeurosis. I did not attempt to dissect out the vessels and nerves, for these were of such small size that the time occupied would have been more than I had at my disposal. I next proceeded to clear the bones of all muscles, \&c., and to investigate the condition of the various articular surfaces. The clavicle appeared to be quite normal, there being free movement at both the sterno-clavicular and acromio-clavicular joints; but it was otherwise with 
the scapula, its axillary edge differing considerably from the normal anatomy of that part. The most pro. minent feature of the scapula is the condition of the coracoid process. Instead of being the normal small

FIG. 1.

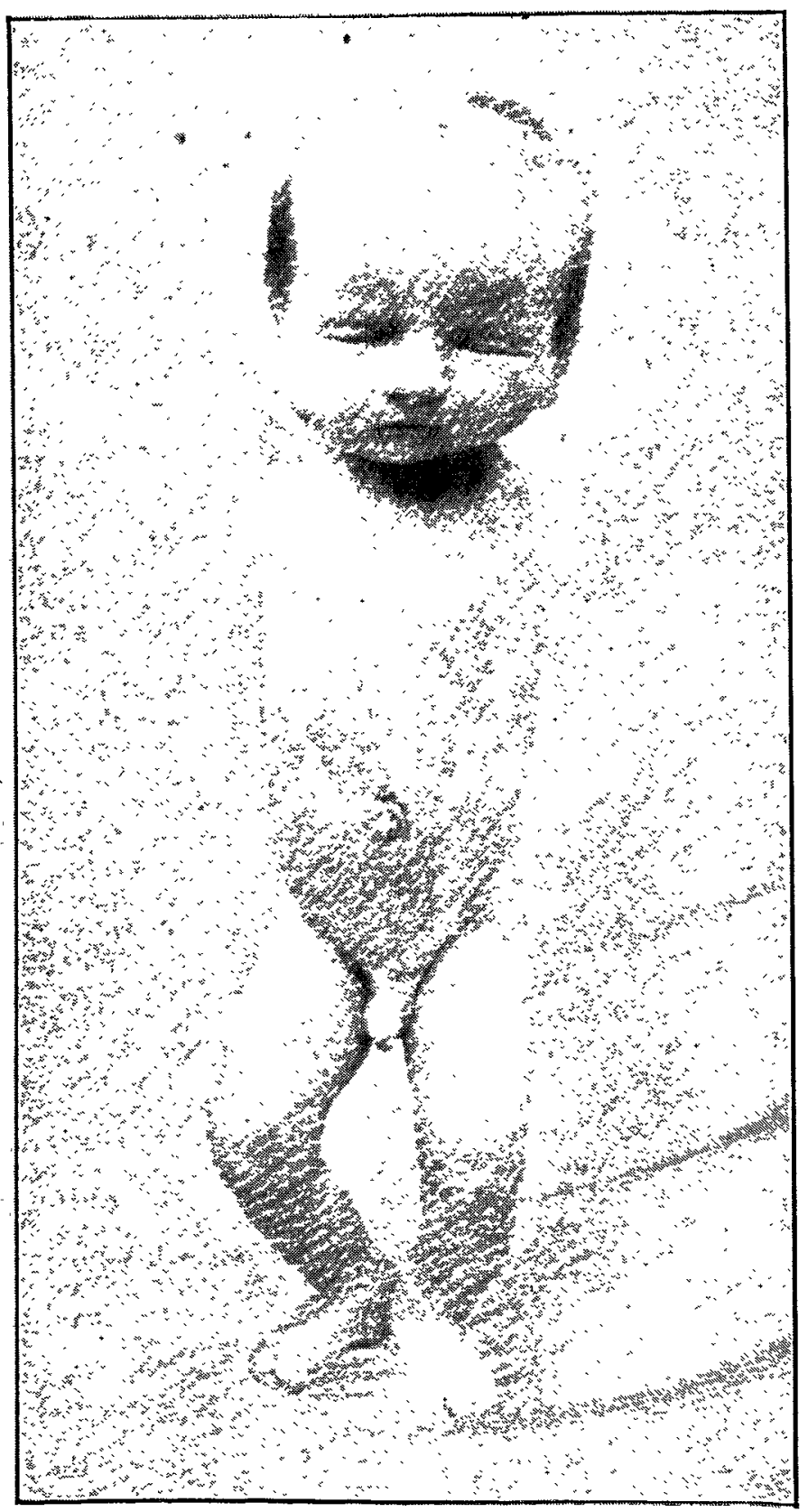

A case of congenital deficiency of the upper extremities.

FIG. 2.

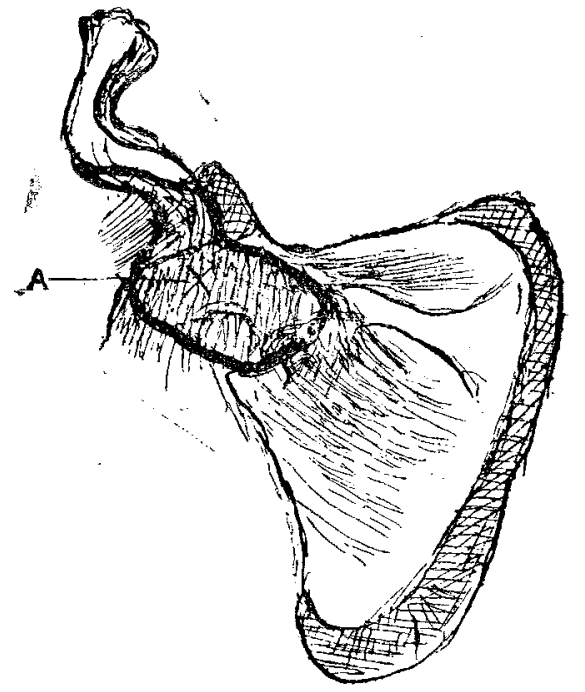

Diagram to show approximate area of aponeurosis. A, Aponeurosis. process, curved forward beneath and in front of the clavicle, it consists of one big process, being the continuation upwards of the body of the scapula. This extended behind, beneath, and above the clavicle, and there was a small articular surface between it and the clavicle. The tip of the process was capped with a large piece of articular cartilage. The size of this process, I presume, might be accounted for by the fact that owing to some error in development the cartilages of the glenoid cavity and the tip of the coracoid process had become fused into one common cartilage, possibly owing to some accidental jarring of the foetus in utero, but this could scarcely cause a symmetrical deformity. There is an attempt at a glenoid cavity at the axillary end of the base of the spine of the scapula in the shape of a small boss of bone with small articular surface placed inferiorly to the spine of the scapula. Its position can just be seen underneath the aponeurosis (A) in Fig. 2. The acromio-clavicular joint was quite normal but for a large amount of fibrous tissue forming the aponeurosis arising from it. There were no signs of a coracoacromial ligament. The biceps and all muscles which usually connect the two bones with the humerus appeared to be entirely absent.

I am greatly indebted to Mr. Thomas C. Pinny of Harlestone, Northampton, for the photograph illustrating the case. Burgess Hill.

\section{ON THREE CASES OF SUPRARENAL APOPLEXY IN CHILDREN.}

By FREDERIOK LANGMEAD, M.B. LoND., M.R.C.S. ENG, MEDICAI REGISTRAR TO THE HOSPITAL FOR SICK CHILDREN, GREAT ORMOND-STREET ; IAATE RESIDENT OBSTETRIC OFFICER, ST. MABY'S HOSPITAX.

THE possibility of almost sudden death in infants being due to hæmorrhage into the suprarenal capsules is so little recognised and so little is known about this disease that it seems worth while to record the following three cases with which I have come in contact.

OASE 1. - The patient was a baby, aged three days. The confinement was attended by St. Mary's Hospital Maternity Charity. He was a full term child and labour was easy. He never breathed freely ; he cried but not vigorously; however, he got a fairly good colour and death was not anticipated. On the morning of the third day the breathing became grunting in character and the child moaned and refused to take the breast. On the same evening he had a general convulsion, with loss of consciousness, became black in the face, blood ran from the nose and mouth, and he died in half an hour.

Post-mortem examination showed the child to be fairly well nourished. The neck, the head, and the face were covered with a purpuric eruption. The navel was quite sweet. There were no marks of violence. The internal organs were all normal with the exception of the lung and the suprarenal bodies. The right heart was distended. The lower lobe of the right lung contained a large hæmorrhage which had burst through the bronchioles and could be traced up into the trachea and larynx and was evidently the source of the blood seen externally. The suprarenal bodies were reddish-purple in colour and stood out against the posterior abdominal wall. They were equally implicated and were moderately distended with what proved to be on section recent blood extravasation. Hrmorrhage was confined to the suprarenals, the surrounding structures being unaffected. The family history was not relevant. The mother had had three other children; there had been no miscarriages and there was no family disease.

CASE 2.-The patient was a boy, an only child, two months old. He had been entirely breast-fed and had been perfectly healthy. He took the breast well and there had been no gastro-intestinal disturbance. On Feb. 29th, 1804, the mother fed him at 11 P.M. ; he took the breast and she noticed nothing wrong and afterwards he went to sleep. On the next morning at $5 \mathrm{~A} . \mathrm{M}$. the mother noticed a change; the child was breathing heavily. She said, however, that the colour was good, that there was no loss of consciousness, that the fists were not clenched, and that there were no squint, no sort of fit, and no screaming or apparent pain. The natural functions were performed normally. The mother could not get the child to suck. However, he went to sleep 